\title{
Desenvolvimento do aplicativo XÔ ZIKA para Android: Tecnologia educacional aplicada na área de saúde
}

\author{
Cleber Fernando Serafin ${ }^{1}$, Felipe José Rezende de Carvalho ${ }^{1}$, Marcos Fernando \\ Schmitt $^{1}$, João Vitor Zarth ${ }^{1}$ \\ ${ }^{1}$ Técnico Integrado em Cooperativismo - IFPR - Capanema - PR - Brasil \\ \{cleber.serafin,felipe.carvalho,marcos.schmitt\}@ifpr.edu.br, manoloae2@hotmail.com
}

\begin{abstract}
Contemporaneously Brazil is plagued by a great evil: the proliferation of the mosquito Aedes aegypti. Our region has become endemic with growing number of infected people. Lack of awareness and collaboration of the population contributes to the growth of this problem. In order to improve the knowledge of people about this issue, helping to combat the problem, we have developed the free app Xô Zika for mobile devices with Android operating system. He has issues involving the subject in question in the quiz format. In addition, the application has a form so that people can send anonymous complaints of a possible focus. This is sent by the developer team to the competent local authorities.
\end{abstract}

Resumo. Contemporaneamente o Brasil é assolado por um grande mal: a proliferação do mosquito Aedes aegypti. Nossa região tem se tornado endêmica com número crescente de pessoas infectadas. A falta de conscientização e colaboração da população contribui para o crescimento desse problema. Com o objetivo de melhorar o conhecimento das pessoas sobre essa questão, auxiliando no combate ao problema, desenvolvemos o aplicativo gratuito Xô Zika para dispositivos móveis com sistema operacional Android. Ele conta com questões envolvendo a temática em questão no formato de quiz, além disso, dispõe de um formulário para que a população possa enviar denúncias anônimas de um possível foco às autoridades competentes.

\section{Introdução}

As tecnologias digitais estão cada vez mais presentes nos diversos setores da sociedade, não só no que tange a comunicação, mas também como recurso de ensino e aprendizagem. Segundo pesquisa da Jana (2015), o Brasil conta com 49 milhões de dispositivos móveis, podendo chegar a 72 milhões em 2018, sendo que 90\% deles contam com sistema operacional Android. O número de usuários desse sistema operacional livre vem crescendo ano a ano, os quais eram de 72,6\% em 2012 e 85,1\% em 2013 considerando pesquisa da Gartner (2013).

Levando em conta a ampla difusão desses dispositivos e a necessidade de conscientizar a população sobre o grande problema da proliferação do mosquito Aedes aegypti que é agente etiológico de várias doenças, nada melhor que juntar as informações necessárias com esse meio de comunicação para alcançar a população. Fazse necessário então um aplicativo que pudesse ser educativo, interativo e recreativo, com intuito de apresentar os problemas que envolvem esse mosquito.

Segundo Fontes (2002), o processo de aprendizagem que utiliza de recursos digitais e as Novas Tecnologias da Informação (NTI), possui condições inovadoras de produção do conhecimento. Esse contexto institui diferenciadas formas de comunicação 
e organização de mensagens entre seus usuários.

Neste trabalho, apresentamos o estado atual de desenvolvimento do nosso aplicativo Xô Zika, que conta com questões em um jogo quiz, além de uma tela que propicia ao usuário fazer denúncias anônimas de possíveis criadouros do Aedes aegypti.

A seção 2, o artigo explana sobre os materiais e métodos utilizados no desenvolvimento do projeto. Já na seção 3, é comentado um pouco sobre a ferramenta App inventor. A seção 4 apresenta uma discussão juntamente aos resultados parciais e, por fim, apresenta-se uma conclusão.

\section{Material e Métodos}

Em um momento de descontração, alguns professores do IFPR Campus Capanema - PR, debatiam sobre possíveis formas de conscientização da população para reduzir a multiplicação do Aedes aegypti, problema que assola a população em quase todo Brasil. Com o crescimento da utilização de dispositivos móveis, o desenvolvimento de um aplicativo que, não somente auxiliasse no combate ao mosquito a partir de denúncias de focos, mas também possuísse finalidade educativa à população, pareceu algo promissor a alcançar os objetivos almejados.

Delineada a ideia, foi traçado o planejamento e as metas sobre sua execução. Para isso, foi feita uma chamada interna entre os discentes do primeiro ano do curso Técnico Integrado de Cooperativismo, para que tivessem a oportunidade de participar do trabalho, selecionando-se assim o aluno João Zarth. O mesmo ajudou a equipe com sugestões no projeto e também com seu desenvolvimento, convergindo para a idealização do aplicativo Xô Zika a partir do framework App Inventor.

O desenvolvimento do aplicativo teve início no começo do mês de março de 2016. Criou-se um roteiro de produção com as etapas e as funções necessárias para o mesmo. Definiu-se que seria um jogo no formato quiz e que teria uma tela para denúncia anônima de possíveis focos. O banco de perguntas apresentadas no quiz foi formulado com a colaboração de um professor com formação em Farmácia Bioquímica. Em parceria com o aluno, baseados em documentos oficiais da campanha de combate ao Aedes aegipty fornecidas pelo Ministério da Saúde (2015), as questões foram formuladas. Essas perguntas estão em constante atualização para informar ao usuário de novidades, inclusive notificando sobre novas áreas endêmicas. Também está em desenvolvimento uma nova funcionalidade para o aplicativo, que permitirá o envio de foto dos possíveis criadouros através da tela de denúncias. O aplicativo está disponível para download gratuito na Play Store sob o nome de Xô Zika.

\section{Um pouco sobre o App inventor}

O App inventor é uma plataforma livre de programação com funcionalidades para o desenvolvimento de aplicativos forma trivial, trabalhando com o sistema blockly $^{1}$, permitindo que a criação seja ágil e eficaz, reduzindo a preocupação com detalhes das linhas de código. Apesar de sua simplicidade de manipulação, é uma ferramenta robusta e dispõe de uma enorme gama de recursos, atendendo às necessidades do projeto.

A tecnologia de blocos do App Inventor foi desenvolvida a partir da biblioteca Open Blocks para Java, que é distribuída pelo STEP (Scheller Teacher Education Program) do MIT (Massachusetts Institute of Technology). Uma das vantagens desse

1 Biblioteca para programação visual baseada em blocos. 
framework é que pode ser executado de qualquer lugar, ou seja, a plataforma de desenvolvimento está localizada na web, baseando-se nas cloud computing ${ }^{2}$. Vale ressaltar que os aplicativos produzidos por ele podem ser softwares com arquitetura nativa, como é o caso do Xô Zika, que consiste na aplicação elaborada para executar no ambiente do dispositivo móvel.

Um exemplo dessa arquitetura é a utilização do TinyDB, um dos bancos de dados que o framework utiliza. Ele é descarregado no dispositivo móvel toda vez que a aplicação é instalada ou atualizada. Durante a execução do aplicativo, para a interação com a tela de usuário, as perguntas são buscadas desse banco de dados, não sendo necessário conexão com a internet.

\section{Resultados e Discussão}

O aplicativo Xô Zika é uma iniciativa que visa disseminar informações à solução de problemas relacionados à área social, de saúde pública e educacional, utilizando como meio a tecnologia aplicada nos smartphones e tablets. Através de projetos desta natureza, pode-se sensibilizar e provocar uma mudança de comportamento no cidadão a partir de sua interação e investigação, possibilitando que autoridades saibam, quase em tempo real, sobre possíveis criadouros de mosquitos em sua região. O desenvolvimento de aplicativos com propósitos educacionais na área de saúde, especificamente treinamento de inspeção de focos da dengue, mostrou-se uma tarefa inicialmente complexa devido a falta de uma metodologia específica, voltada para o auxílio do Plano de Erradicação do Aedes aegypti na área digital. Uma característica particular do presente projeto, é o fato de ele não estar associado a nenhuma outra iniciativa educacional, e portanto de caráter inovador no que se refere a denúncias on line de focos de dengue. Espera-se cativar o usuário pelo jogo quiz, que está repleto de informações sobre a dengue, que são renovadas e incrementadas periodicamente, permitindo a interação com autoridades municipais responsáveis pelas providências. Observou-se, por outras experiências relatadas na literatura, bem como pelo desenvolvimento deste projeto, que não há uma metodologia apropriada para este tipo de atividade, mas que a Saúde Pública pode se beneficiar muito de ambientes de treinamento, usando a tecnologia de forma simples para melhorar índices de saúde.

Segundo Souza et all (2015), responsáveis pela avaliação da ferramenta denominada de "Avaliação de Mobilidade Precoce", aplicativos desenvolvidos com a plataforma App Inventor podem ser tão úteis quanto outros aplicativos utilizados na área da saúde para a conscientização da população frente a alguma doença.

As denúncias recebidas pela equipe desenvolvedora, sobre possíveis criadouros do mosquito, são prontamente redirecionadas para o setor de controle de dengue do respectivo município.

Ainda está em etapa de finalização e validação através da escala de REEVES, que utiliza critérios em relação à interface com o usuário (14 critérios) e em relação aos aspectos pedagógicos do aplicativo (10 critérios). Esse método avalia o aplicativo com base na pontuação em escala de conceitos antagônicos, levando em conta critérios relacionados à interface com o usuário (facilidade de navegação, design da tela, compatibilidade espacial do conhecimento, apresentação da informação, estética e funcionalidade) e critérios pedagógicos (epistemologia, sequenciamento instrucional, validade experimental, valorização do erro, estruturação, controle do aluno e aprendizado cooperativo). A avaliação está sendo realizada continuamente durante o

2 Computação em nuvens. 
desenvolvimento do aplicativo pela equipe responsável, a fim de assegurar os objetivos e metas propostos originalmente.

\section{Conclusões}

Neste trabalho foram apresentadas as etapas do desenvolvimento de um aplicativo Android em forma de jogo de perguntas e respostas com a possibilidade de efetuar denúncias anônimas sobre possíveis criadouros do Aedes aegypti: o Xô Zika. Acredita-se que ele auxiliará estudantes do ensino médio, professores e profissionais da área de Saúde Pública a aumentarem seus conhecimentos sobre esse problema. Cabe ressaltar o papel motivador do número de acertos nas perguntas, trazendo conteúdos significativos e compreensíveis, além de métodos adequados de combate ao mosquito, o que possivelmente auxiliará no processo de ensino e aprendizagem. Destaca-se ainda que o contato do aluno com o desenvolvimento de aplicativo para dispositivos móveis poderá proporcionar-lhe uma futura oportunidade de inserção no mercado de trabalho.

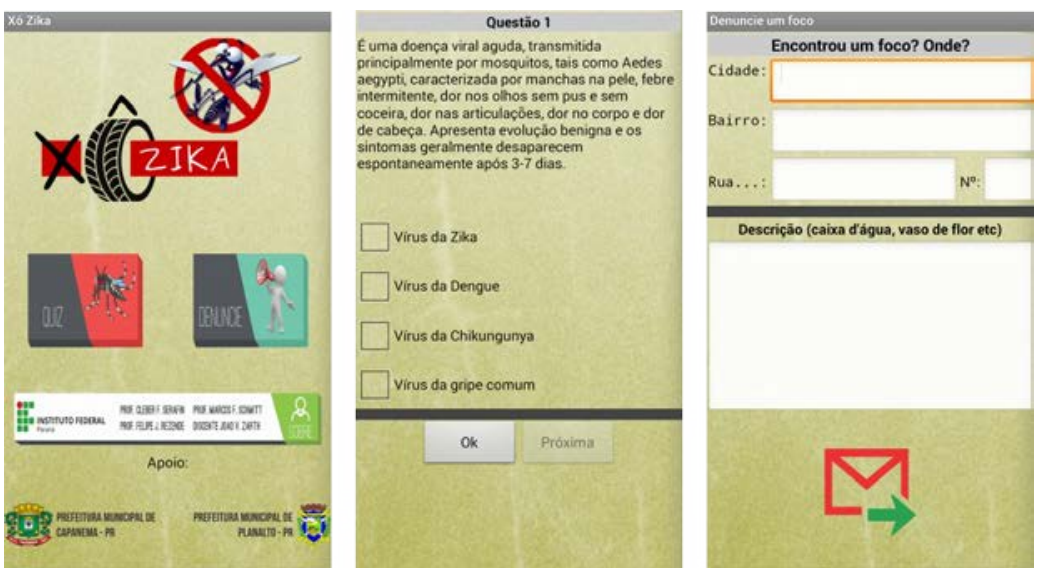

Figura 1: Telas do aplicativo

\section{Referências}

Fontes, M. C. M. (2002) "Aprendizagem de inglês via Internet: descobrindo as potencialidades do meio digital.” São Paulo: PUCSP. Tese (Doutorado em linguística aplicada e estudos da linguagem), Pontifícia Universidade Católica de São Paulo.

Gartner (2013) http://olhardigital.uol.com.br/pro/noticia/samsung-detem-mais-dametade-do-mercado-de-smartphones-no-brasil/40282, Março.

Jana (2015) http://www.tudocelular.com/android/noticias/n61396/Android-BrasilMercado.html, Março.

Lee, V.; Schneider, H.; Schell, R. (2005) “Aplicações móveis: arquitetura, projeto e desenvolvimento.” Pearson, São Paulo.

Ministério da Saúde (2015) http://www.portalsaude.saude.gov.br, Março.

Souza, J. F.; Gonçalves F. B.; Queiroz, V. A. R.; Queiroz, R. S. (2015) "Avaliação de um aplicativo para auxilio à tomada de decisão de mobilizar pacientes críticos." Revista Saúde.com http://www.uesb.br/revista/rsc/v11/v11n1.html, Maio. 